\title{
Investigation of the responses of asphalt pavement structure considering load - Poisson's ratio relation
}

\author{
Zhang Lei ${ }^{1, a}$, Tan Yi-qiu ${ }^{2, b^{*}}$, OuYang Jian ${ }^{3, c}$,Gong Xiang-bing ${ }^{4, d}$
}

${ }^{1}$ School of Transportation Science and Engineering, Harbin Institute of Technology, Harbin 150090, China

${ }^{2}$ School of Transportation Science and Engineering, Harbin Institute of Technology, Harbin 150090, China Corresponding Author.

${ }^{3}$ School of Transportation Science and Engineering, Harbin Institute of Technology, Harbin 150090, China

${ }^{4}$ School of Transportation Science and Engineering, Harbin Institute of Technology, Harbin 150090, China

ahit.andy@foxmail.com, btanyiqiu@hit.edu.cn, cyijianpiaoqian@126.com, 'gongxiangbing@126.com

Keywords: asphalt mixture; deformation properties; Poisson's ratio; response of the structure;

\begin{abstract}
Poisson's ratio is one of the important parameters that can be used to reflect the deformation characteristics of solid materials. To further understand the mechanical behaviors of materials and improve the accuracy of the finite element simulation results, the Poisson's ratio must be defined accurately. In this paper, DIC technology is employed to investigate the Poisson's ratios of asphalt mixtures under the different gradation and different compaction conditions. It is found that the Poisson's ratios of different asphalt mixture are quite different and the number of compaction had a greater influence on Poisson's ratio. It also showed that Poisson's ratio of asphalt mixture was not a constant under the $25^{\circ} \mathrm{C}$ temperature condition, but varied with load. The experiment data suggested that the curve of the load - Poisson's ratio could be divided into three sections through the observation of the graph and it also could be used to investigate the properties of asphalt mixtures deformation resistance. General-purpose finite element software is used to simulate the different contact pressure and Poisson's ratio under dynamic loading condition, in order to find the response of asphalt pavement structure based on the relationship between load and Poisson's ratio. It was found that the relationship of load - Poisson's ratio significantly affected the response of asphalt pavement. It meant that the relationship of load - Poisson's ratio should be considered when designing the asphalt pavement to improve the asphalt pavement service life.
\end{abstract}

\section{Background}

Poisson's ratio $(\mu)$ and elasticity modulus (E) are the two important parameters that characterize the material properties in the elastic theory analysis. In the design of pavement structure, the modulus values of asphalt mixture varies with temperature, however, the value of Poisson's ratio is always taken as a constant, without considering the effect of variation of Poisson's ratio on the response of asphalt pavement structure. Some researchers $[1,2]$ have found that Poisson's ratio increases with the rise of temperature and the content of asphalt. Therefore, it is very important to determine Poisson's ratio under different experimental conditions, such as different temperatures, different kinds of asphalt mixture, to improve the accuracy of the mechanical analysis. To achieve this purpose, the deformation of asphalt mixture should be measured accurately. In most of tests, the deformations of materials are measured by the resistance strain gage or LVDT. Such techniques require a large specimen for strain gage placement and impose tight geometry tolerances to minimize variations of strain at the gage location [3], which make it difficult to prepare the specimens, and hardly to address complex mechanical behavior with just a global stress- strain curve obtained by the classic 
measurement techniques, especially for some heterogeneous materials. Asphalt mixture is a kind of heterogeneous material, wherein its fracture behavior is complicated and difficult to quantify the deformation parameters because of the difficulties of the observation of the fracture process, especially when the cracks first initiate, they are tiny and random occurrence because of the irregularly shaped and randomly oriented aggregate particles and mastic $[4,5]$.

To obtain more experimental information, such as microscopic information of the asphalt mixture deformation processes to improve the identification procedures for this type of material, a high resolution and full-field measurement methods are required. One of them is the Digital Image Correlation (DIC) technique [6,7], an optical and noncontact measurement technique, which is based on a comparative analysis of digital images of the structural member captured at different deformation states. This technique has been applied successfully to various classes of mechanical and civil engineering materials and structural problems [8-11]. There are also some applications to asphalt mixture. Arasan et al.[12]quantified the morphological characteristics of coarse aggregates with digital image processing approach. Kim et al.[13]found that typical dense-graded asphalt mixtures could be characterized for their material properties with an approximate RVE size of $60 \mathrm{~mm}$ with the help of DIC technique. Montepara et al. [14] and Birgisson et al. [8]investigated the cracking behavior of HMA mixtures with DIC system and demonstrated the DIC technique overcome the shortcomings of traditional on-specimen strain measurement devices achieving satisfactory accuracy compared to strain gauges.

In this paper, DIC method is introduced to determinate the full-field strain produced by IDT (indirect tension test) to obtained load- Poisson's ratio relation of different asphalt mixtures, and then, the responses of asphalt pavement structure considering load- Poisson's ratio relation will be analyzed by general-purpose finite element software.

\section{Materials and experiments}

\subsection{Materials used}

\subsubsection{Asphalt and grading}

The basic properties of the binder used in this study as per Chinese specifications (JTJ052-2000) are shown in Table 1.

Table 1 The Basic Properties of Asphalts

\begin{tabular}{|c|c|c|c|c|}
\hline Evaluation index & Unit & $\begin{array}{c}\text { Technical } \\
\text { requirements }\end{array}$ & Test results & $\begin{array}{c}\text { Test method } \\
(\mathrm{JTJ} 052-2000)\end{array}$ \\
\hline Penetration $\left(25^{\circ} \mathrm{C}, 100 \mathrm{~g}, 5 \mathrm{~s}\right)$ & $0.1 \mathrm{~mm}$ & $60 \sim 80$ & 66 & T0604-2000 \\
\hline Softening Point $\left(\mathrm{T}_{\mathrm{R} \& \mathrm{~B}}\right)$ & ${ }^{\circ} \mathrm{C}$ & $\nless 55$ & 69.2 & T0606-2000 \\
\hline Ductility $5^{\circ} \mathrm{C}(5 \mathrm{~cm} / \mathrm{min})$ & $\mathrm{cm}$ & $\$ 30$ & 33.9 & T0605-1993 \\
\hline $\begin{array}{c}\text { Elastic Recovery }\left(25^{\circ} \mathrm{C}, 5 \mathrm{~cm} / \mathrm{min}\right. \\
, 1 \mathrm{~h})\end{array}$ & $\%$ & $\nless 65$ & 92.7 & Т0662-2000 \\
\hline Storage Stability & ${ }^{\circ} \mathrm{C}$ & $\ngtr 2.5$ & 1.2 & T0661-2000 \\
\hline
\end{tabular}

The gradations used in this research are shown in Table 2.

Table 2 Passing percentage of mineral mixtures (\%)

\begin{tabular}{c|c|c|c|c|c|c|c|c|c}
\hline Sieve Sizes(mm) & 16 & 13.2 & 9.5 & 4.75 & 2.36 & 1.18 & 0.6 & 0.3 & 0.075 \\
\hline AC-16 & 88.7 & 72.8 & 45.3 & 30.8 & 21.0 & 15.4 & 11.8 & 8.0 & 6.0 \\
\hline AC-13 & 95.9 & 75.3 & 46.0 & 31.5 & 21.0 & 15.4 & 11.8 & 8.0 & 6.0 \\
\hline
\end{tabular}

The filler used is limestone powder passed through a 200 sieve and the specific gravity of it is 2.740. The polyester fiber (BoniFibers ${ }^{\circledR}$ ) content added in the designed asphalt mixture is $0.3 \%$ by weight.

\subsubsection{Mixture design}

The mix design procedures for AC-16 and AC-13 in this paper are determined as per the Chinese specification JTJ052-2000 (T0703-1993). Locally available materials that meet the normal AC-16 and $\mathrm{AC}-13$ specifications are used to produce the mixes. With the asphalt and gradation mentioned 
above, five kinds of asphalt mixture (A, B, C, D and E) are made by gyrat ory compaction under the condition of optimal asphalt content to maintain consistency through the study. The results are shown in the following Table 3.

Table 3 The Category of Asphalt Mixtures

\begin{tabular}{c|c|c|c}
\hline \multirow{2}{*}{ Mixture type } & $\begin{array}{c}\text { The number of gyratory } \\
\text { compaction }\end{array}$ & Asphalt content (\%) & Mixture ID \\
\hline \multirow{3}{*}{ AC-13 } & 90 & 5.2 & $\mathrm{~A}$ \\
\cline { 2 - 4 } & 125 & 5.2 & $\mathrm{~B}$ \\
\cline { 2 - 4 } & 205 & 5.2 & $\mathrm{C}$ \\
\hline \multirow{2}{*}{ AC-16 } & 125 & 4.7 & $\mathrm{D}$ \\
\cline { 2 - 4 } & 205 & 4.7 & $\mathrm{E}$ \\
\hline
\end{tabular}

\subsection{Experimental part}

\subsubsection{Method of loading}

Indirect tension test (IDT) is one of methods widely used in engineering practice to evaluate the mechanical performance of mixture samples under loading $[15,16]$, which is employed in this research. Laboratory specimens are prepared using Superpave Gyratory Compactor. The specimens are placed in a temperature chamber set to $25^{\circ} \mathrm{C}$ for $12 \mathrm{~h}$ prior to the IDT test, and the test is done using Materials Testing System (MTS-810). The tests are conducted at $25^{\circ} \mathrm{C}$ temperature, $10 \mathrm{~mm} / \mathrm{min}$ loading rate to monitor the deformation behavior of mixes with DIC technology.

\subsubsection{Method of measuring deformation}

In this research, Vic-3D 2010 produced by Correlated Solutions, Inc. was employed. This system is a complete, turn-key system for measuring the shape, displacement and strain of surfaces in three dimensions [17]. The optics adopted at maximum magnification allows 0.01 per pixel resolution. The camera was set up at a distance away from the specimen so that the resulting imaging window was focused on the whole surface of specimen, where Region Of Interest (ROI) is. Once the image sequence of the fracture test has been acquired, the features on the specimen surface are tracked along the sequence to obtain image coordinates.

\section{Results and discussion}

\subsection{Poisson's ratio test results and discussion}

Poisson's ratio is one of the fundamental properties of any engineering material. Knowing the value of Poisson's ratio of asphalt mixture is important for evaluation and simulations.

\subsubsection{Poisson's Ratio of different asphalt mixture}

The ratio between transverse strain $\varepsilon_{x}$ and longitudinal strain $\varepsilon_{y}$ is defined as Poisson's ratio $=-\varepsilon_{x} / \varepsilon_{y}$. From DIC test, $\varepsilon_{x}$ and $\varepsilon_{y}$ can be obtained, and then the can be calculated as per above formulation. The results are shown in Fig. 1 and Fig. 2 [18].

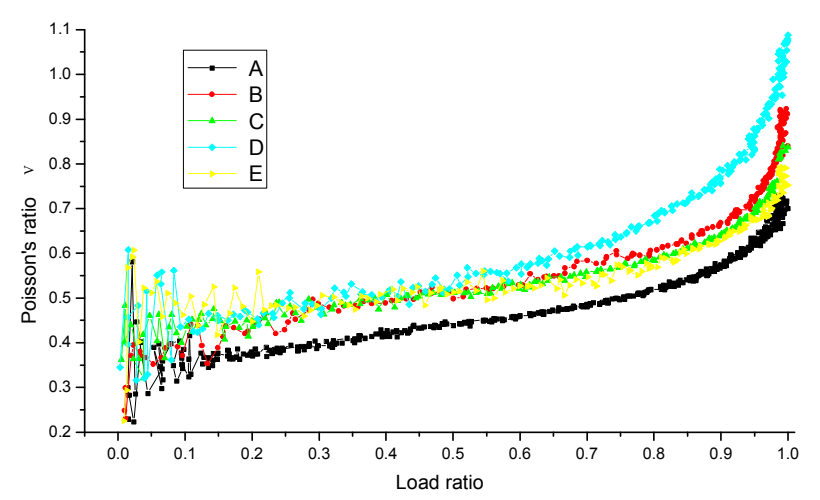

- Load ration $=P / P_{\max }$.

Fig. 1 Curve of Load ration-Poisson's ration

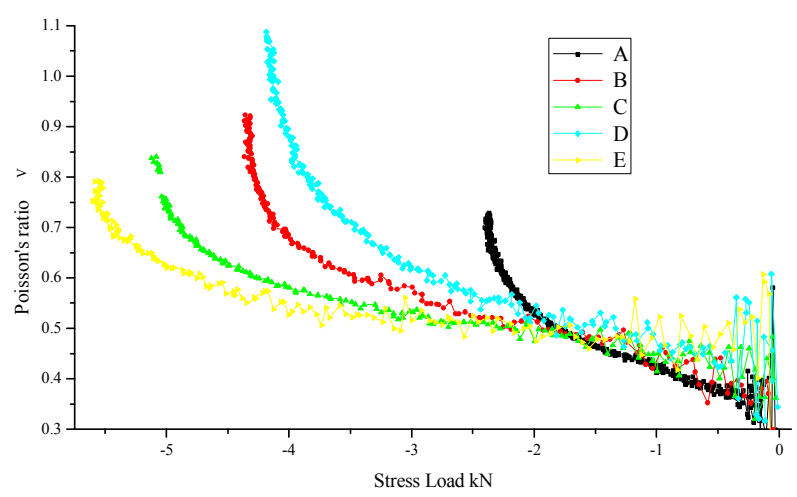

Fig. 2 Curve of Load -Poisson's ration 
From Fig.s 1 and 2 it can be found that all the Poisson's ratio of mixture in the initial load are unstable, because of compression process; With the load increasing, Poisson's ratio tends to a stable and linear growth; When the load (or load ratio) exceed a certain point, the Poisson's ratio increases rapidly, eventually leading to destruction of the specimen. Therefore, the load - Poisson's ratio curve can be divided into three phases: initial compression phase, stable development phase and critical limit phase. It is also can be concluded from Fig. 1 and 2 that the Poisson's ration is not a constant for asphalt mixture at $25^{\circ} \mathrm{C}$, it is related with the load magnitude.

From Fig. 1 and 2, it can be found that gyratory compaction time has a great influence on Poisson's ration. The fewer gyratory compaction times, the shorter second phase of the load - Poisson's ratio curve and the higher growth rate; it is adverse to mixture performance.

\subsubsection{Modeling Poisson's Ratio of different asphalt mixture}

It can be known that the Poisson's ration is not a constant from the above result, to improve the computer simulations results, the relationship between Poisson's ration and load should be investigated. In this research, Burges model $y=1 /[1 / a+x / m+1 / b *(1-\exp (-x * b / n))]$ is employed to evaluate the relationship of them, the curves are fitted by Origin ${ }^{\circledR} 8.1$ software. To eliminate the negative effects of the first phase, the fitting starts at $-0.5 \mathrm{kN}$. The results are shown in Table 4.

Table 4 Fitting results

\begin{tabular}{c|c|c|c|c|c}
\hline \multirow{2}{*}{$\begin{array}{c}\text { Asphalt } \\
\text { mixture } \\
\text { type }\end{array}$} & \multicolumn{4}{|c|}{ Fitting Function: $\mathrm{y}=1 /\left[1 / \mathrm{a}+\mathrm{x} / \mathrm{m}+1 / \mathrm{b}^{*}(1-\exp (-\mathrm{x} * \mathrm{~b} / \mathrm{n}))\right]$} & \multirow{2}{*}{$\mathrm{R}^{\wedge} 2$} \\
\cline { 2 - 6 } & $\mathrm{a}$ & $\mathrm{m}$ & $\mathrm{b}$ & $\mathrm{n}$ & \\
\cline { 2 - 6 } & 3.0159 & -11.0824 & -4085034.05 & -728566.80 & 0.99 \\
\hline $\mathrm{A}$ & 2.5961 & -16.9402 & -123754201.91 & -31285823.93 & 0.98 \\
\hline $\mathrm{B}$ & 2.3988 & -26.9984 & -1151465.34 & -480636.92 & 0.99 \\
\hline $\mathrm{C}$ & 2.5207 & -13.8309 & -1467960.42 & -466329.25 & 0.99 \\
\hline $\mathrm{D}$ & 2.28933 & -36.8260 & -1765410.79 & -778828.82 & 0.98 \\
\hline $\mathrm{E}$ & &
\end{tabular}

It is can be found that Burges model can fit load - Poisson's ratio curve well, and correlation coefficients are all above 0.98 .

\subsection{Finite element simulation results and discussion}

To further investigate the effect of load - Poisson's ratio on the responses of asphalt pavement structure, general-purpose finite element software is employed in this part.

\subsubsection{The establishment of finite element model}

\subsubsection{Establishment of the model}

Studies have shown when the size of the pavement structure model is greater than $5 \mathrm{~m} \times 5 \mathrm{~m} \times 5 \mathrm{~m}$, structural size has little effect on the calculation results. In this paper, the model size is $6 \mathrm{~m} \times 5 \mathrm{~m} \times 5 \mathrm{~m}$. The structure of pavement is shown in Table 5.

Table 5 Structure of pavement

\begin{tabular}{c|c|c}
\hline Thickness & Possition & Material parameters \\
\hline $4 \mathrm{~cm}$ & AC-16 & $\mathrm{E}=1200 \mathrm{Mpa}$, \\
\hline $6 \mathrm{~cm}$ & AC-20 & $\mathrm{E}=1200 \mathrm{Mpa}$ \\
\hline $8 \mathrm{~cm}$ & AC-25 & $\mathrm{E}=1100 \mathrm{Mpa}, \mu=0.35$ \\
\hline $36 \mathrm{~cm}$ & $\begin{array}{c}\text { Cement-stabilized crushed } \\
\text { stones }\end{array}$ & $\mathrm{E}=1500 \mathrm{Mpa}, \mu=0.25$ \\
\hline $20 \mathrm{~cm}$ & Cement-stabilized gravel & $\mathrm{E}=2000 \mathrm{Mpa}, \mu=0.30$ \\
\hline-- & Subgrade & $\mathrm{E}=50 \mathrm{Mpa}, \mu=0.40$ \\
\hline
\end{tabular}

All materials are considered as the elastic material, each structural layer of the pavement is completely continuous contact; the model around boundary is restricted to generate Longitudinal, horizontal and normal displacement, but it can rotate about the normal axis, the bottom cannot move vertically. The element type of FEM model is reduced integrated quadratic three dimensional octahedrons (C3D8R). Then apply more seeds on the area of wheel loading and asphalt mix layers. 
Calling subroutine written by FORTRAN through Dload port Abaqus to apply dual-wheeled uniform moving load on model. To eliminate the edge effect and shorten the computation time, the longitudinal end of model on both sides of $0.5 \mathrm{~m}$ is not applied load, only applying load on the middle of model. The region of load is shown in Fig. 3.

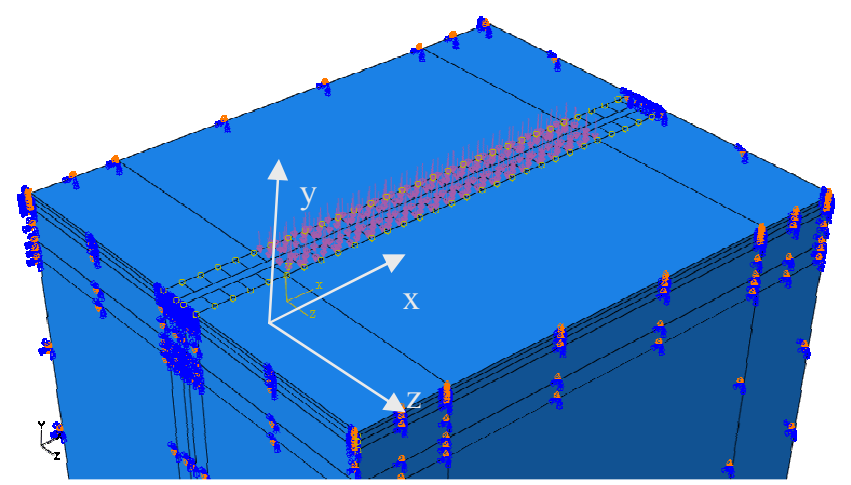

Fig. 3 The region of load

\subsubsection{Study cases}

To study the effect of load- Poisson's ratio relation on the responses of asphalt pavement structure qualitatively, according to the above test results, six cases are determined, they are shown in Table 6 and Table 7.

Table 6 Load and material parameters in different cases

\begin{tabular}{c|c|c|c|c|c|c|c}
\hline \multicolumn{2}{c|}{ Case } & 1 & 2 & 3 & 4 & 5 & 6 \\
\hline \multicolumn{2}{c}{ Pressure (Mpa) } & 0.7 & 0.9 & 0.9 & 1.1 & 1.1 & 0.7 \\
\hline \multirow{2}{*}{$\begin{array}{c}\text { Poisson's } \\
\text { ratio }\end{array}$} & $\begin{array}{c}\text { Top } \\
\text { surface }\end{array}$ & 0.35 & 0.35 & 0.40 & 0.45 & 0.35 & 0.40 \\
\cline { 2 - 7 } & $\begin{array}{c}\text { Mid } \\
\text { surface }\end{array}$ & 0.35 & 0.35 & 0.38 & 0.40 & 0.35 & 0.38 \\
\hline
\end{tabular}

Table 7 Material parameters in other layers

\begin{tabular}{c|c|c|c|c}
\hline Materials & Lower surface & Top base & Lower base & Earth subgrade \\
\hline $\begin{array}{c}\text { Poisson's } \\
\text { ratio }\end{array}$ & 0.35 & 0.25 & 0.30 & 0.40 \\
\hline
\end{tabular}

\subsubsection{Determination of observation position}

Studies have shown that the point directly below the wheel load is the most adverse point under static loads. So in this paper, the stress and strain of this point are investigated.

\subsubsection{Results and analysis}

\subsubsection{The structural response in various pressures and Poisson's ratio}

In this section, Case 1 and Case 6 are selected. The simulation results are shown in Fig. 4.
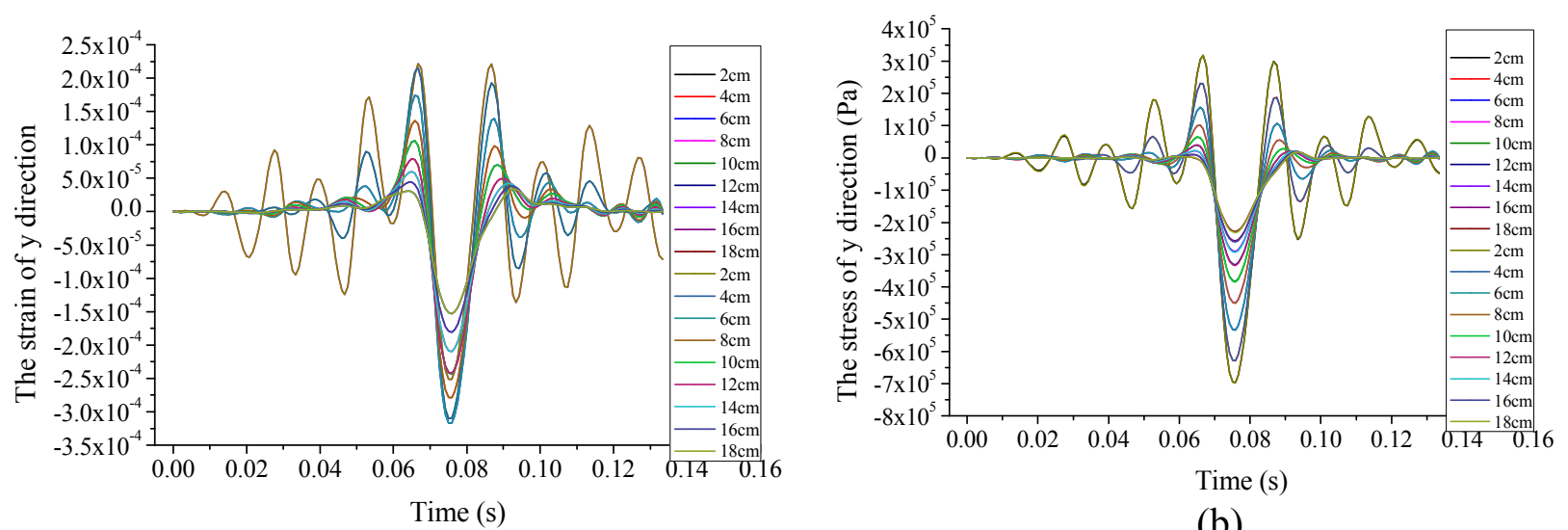

(b) 
(a)

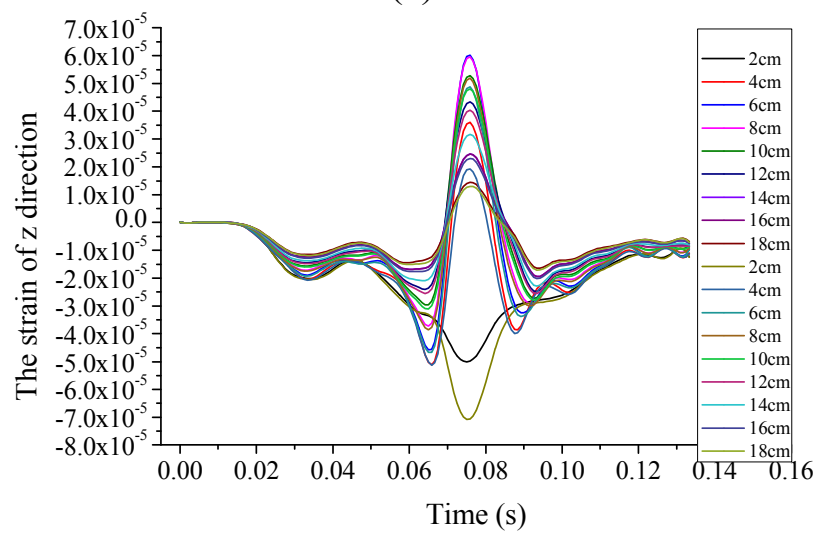

(c)

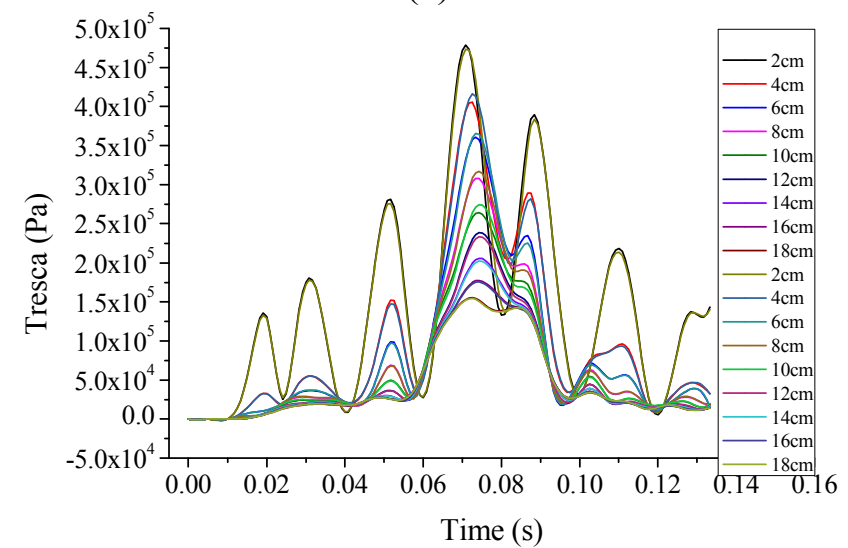

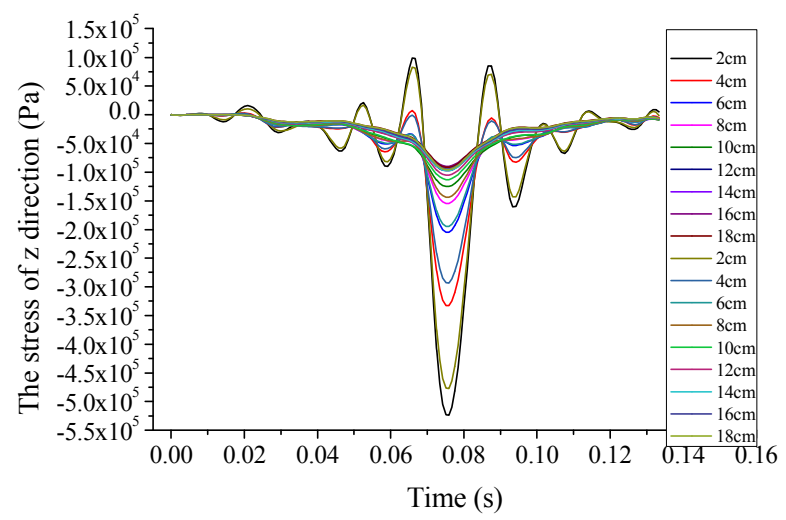

(d)

(e)

Fig. 4 The simulation results of Case 1 and Case 5

It can be inferred from Fig. 4 that with the load close to the observation point there is a slight stress and strain response; and when the load on the observation point, the response amplitude of structure is max. The stress-strain responses of different depths have the same trend, but different amplitude. From Fig. 4-a and Fig. 4-b it can be found that when the load moves to the observation points, the state of these points are not only the process of compressive stress (compressive strain) formation and dissipation; these points subject to tensile stress before the compressive stress (compressive strain). It means that when load passing, the pavement will subject the compression and shear process. From Fig. 4-c it can be found that when the load on the observation point, there is tensile strain in the direction of z. It also can be inferred from Fig. 4 that when Poisson's ratio changed, the amplitude of responses will be effect, but the laws of responses will be the same.

There is the same law between Case 2 and Case 3 and between Case 4 and Case 5, whose results are not shown in this paper.

\subsubsection{The asphalt pavement structural response considering load- Poisson's ratio relation}

To study the effect of load- Poisson's ratio relation on pavement structural response, the strain of $z$ direction at the depth of $6 \mathrm{~cm}$ in Case 1, 2, 3, 4 and 5 are plotted in Fig. 5. 


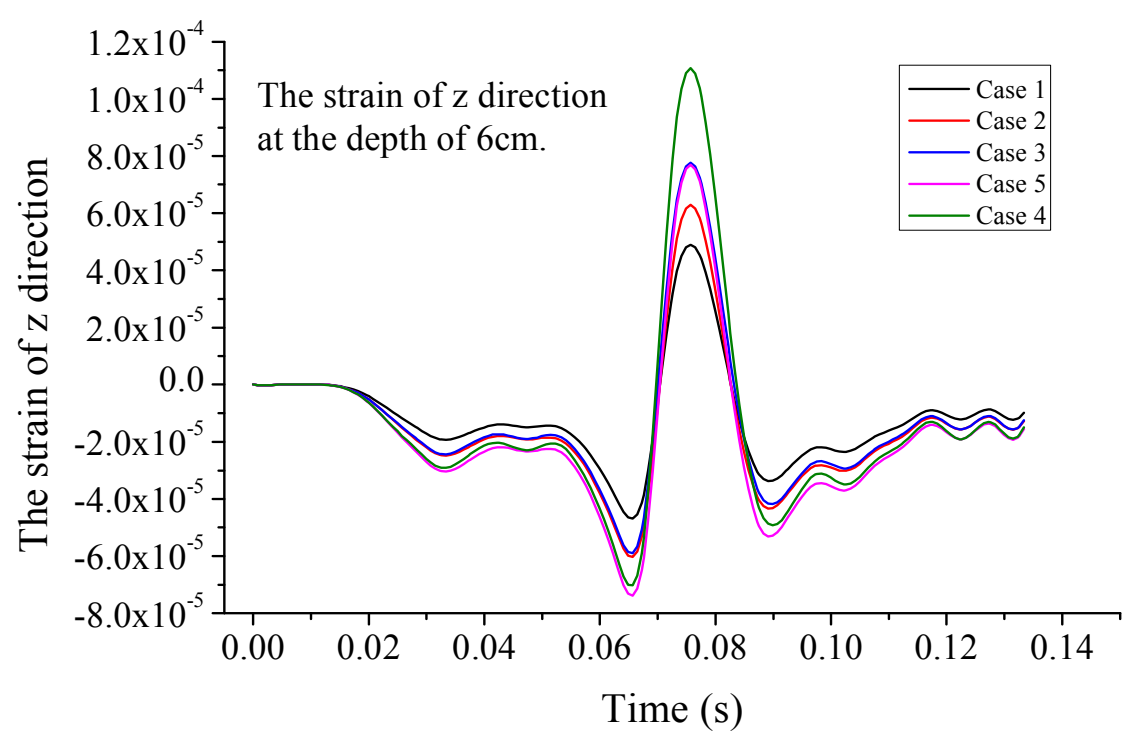

Fig. 5 The strain of $z$ direction under different Cases.

From Fig. 5 it can be found that whether or not to consider the load- Poisson's ratio relation, the strain of $\mathrm{z}$ direction at the depth of $6 \mathrm{~cm}$ will be increased varied with the increase of the load. When without considering the load- Poisson's ratio relation, the increase of transverse deformation is $29.5 \%$ when the load increases from $0.7 \mathrm{Mpa}$ to $0.9 \mathrm{Mpa}$; when the load increases from $0.7 \mathrm{Mpa}$ to $1.1 \mathrm{Mpa}$, the increase of transverse deformation is $57.6 \%$. However, when considering the load- Poisson's ratio relation, the increase of transverse deformation is $59.6 \%$ when the load increases from $0.7 \mathrm{Mpa}$ to $0.9 \mathrm{Mpa}$; when the load increases from $0.7 \mathrm{Mpa}$ to $1.1 \mathrm{Mpa}$, the increase of transverse deformation is $127.5 \%$. It means that the load- Poisson's ratio relation has the significant effect on the transverse deformation of asphalt pavement. The greater load, the more significant effect.

Excessive transverse deformation would lead to transverse flow, which is one of the reasons that lead to rut. Therefore, the load- Poisson's ratio relation should be considered when designing the asphalt pavement, especially in heavy-load and overload pavement, to ensure the pavement life.

\section{Conclusions}

Based on the testing and analysis presented herein, the conclusions of the study are summarized as follows:

(1) The load - Poisson's ratio curve can be divided into three phases and the Poisson's ratio is not a constant for asphalt mixture at $25^{\circ} \mathrm{C}$, it is related with the load magnitude; The number of gyratory compaction has the great effect on the deformation properties of asphalt mixture, the more number of gyratory compaction, the better deformation resistance.

(2) When load passing, the pavement will subject the compression and shear process. When the load is on the observation point, there is tensile strain in the direction of $\mathrm{z}$. It also can be inferred from Fig. 6 that when Poisson's ratio changed, the amplitude of responses will be effect, but the laws of responses will be the same.

(3) Whether or not to consider the load- Poisson's ratio relation, the strain of $\mathrm{z}$ direction at the depth of $6 \mathrm{~cm}$ will be increased varied with the increase of the load, but the load- Poisson's ratio relation has the significant effect on the transverse deformation of asphalt pavement. The greater load, the more significant effect.

(4) Excessive transverse deformation would lead to transverse flow, which is one of the reasons that lead to rut. Therefore, the load- Poisson's ratio relation should be considered when designing the asphalt pavement, especially in heavy-load and overload pavement, to ensure the pavement life. 


\section{Acknowledgement}

The authors are grateful to the financial support by National Natural Science Foundation of China (50808058 \& 51101138), and many thanks should be given to Guo Meng for his help.

\section{References:}

[1] Palit, S.K., Reddy, K.S.,Pandey, B.B. Laboratory evaluation of crumb rubber modified asphalt mixes. J Journal Of Materials In Civil Engineering, 2004, 16(1), 45-53.

[2] SHAO, X., SHAO, M., BI, Y.,SUN, L. Testing Method of Asphalt Mixture Poisson Ratio. J Journal of Tongji University(Natural Science), 2006(11), 1470-1474.

[3] Makeev, A., Ignatius, C., He, Y.H.,Shonkwiler, B. A Test Method for Assessment of Shear Properties of Thick Composites. J Journal Of Composite Materials, 2009, 43(25), 3091-3105.

[4] Kim, H., Wagoner, M.P.,Buttlar, W.G. Micromechanical fracture modeling of asphalt concrete using a single-edge notched beam test. J Materials And Structures, 2009, 42(5), 677-689.

[5] Issa, M.A., Islam, M.S.,Chudnovsky, A. Size effects in concrete fracture - Part II: Analysis of test results. J International Journal Of Fracture, 2000, 102(1), 25-42.

[6] Pan, B., Wang, Z.,Xie, H. Generalized spatial-gradient-based digital image correlation for displacement and shape measurement with subpixel accuracy. J Journal Of Strain Analysis For Engineering Design, 2009, 44(8), 659-669.

[7] Sutton, M.A., Wolters, W.J., Peters, W.H., Ranson, W.F.,McNeill, S.R. DETERMINATION OF DISPLACEMENTS USING AN IMPROVED DIGITAL CORRELATION METHOD. J Image And Vision Computing, 1983, 1(3), 133-139.

[8] Birgisson, B., Montepara, A., Romeo, E., Roncella, R., Roque, R.,Tebaldi, G. An optical strain measurement system for asphalt mixtures. J Materials And Structures, 2009, 42(4), 427-441.

[9] Birgisson, B., Montepara, A., Romeo, E., Roque, R.,Tebaldi, G. Influence of Mixture Properties on Fracture Mechanisms in Asphalt Mixtures. J Road Materials and Pavement Design, 2010, 11, 61-88.

[10] Toussaint, E., Destrebecq, J.F.,Ferrier, E. Analysis of Cracks and Deformations in a Full Scale Reinforced Concrete Beam Using a Digital Image Correlation Technique. J Experimental Mechanics, 2011, 51(6), 879-890.

[11] Jolin, M., Kuntz, M., Bastien, J., Perez, F.,Hild, F. Digital image correlation analysis of crack behavior in a reinforced concrete beam during a load test. J Canadian Journal Of Civil Engineering, 2006, 33(11), 1418-1425.

[12] Arasan, S., Yenera, E., Hattatoglu, F., Hinislioglua, S.,Akbuluta, S. Correlation between Shape of Aggregate and Mechanical Properties of Asphalt Concrete Digital Image Processing Approach. J Road Materials and Pavement Design, 2011, 12(2), 239-262.

[13] Kim, Y., Lee, J.,Lutif, J.E.S. Geometrical Evaluation and Experimental Verification to Determine Representative Volume Elements of Heterogeneous Asphalt Mixtures. J Journal Of Testing And Evaluation, 2010, 38(6), 660-666.

[14] Montepara, A., Romeo, E., Birgisson, B.,Tebaldi, G. Strain Localization and Damage Distribution in SBS Polymer Modified Asphalt Mixtures. J Road Materials and Pavement Design, 2010, 11(4), 899-915.

[15] Lytton, R.L., J. Uzan, E.G.F., R. Roque, D.H.,Stoffels., S. Development and Validation of Performance Prediction Models and Specifications for Asphalt Binders and Paving Mixtures. J Report SHRP-A-357, Strategic Highway Research Program, Washington D.C., USA, 1993.

[16] Buttlar, W.G.,Roque., R. Development and Evaluation of the Strategic Highway Research Program Measurement and Analysis System for Indirect Tensile Testing at Low Temperature. J Report TRB1454, Transportation Research Board, Washington, D.C. USA., 1994.

[17] http://www.correlatedsolutions.com/index.php/products/vic-3d-2010.

[18] Tan Yi-qiu, Zhang Lei, Guo Meng, Shan Li-yan and Zhang Kui. Investigation of the deformation properties of asphalt mixtures with DIC technique. J Construction and Building Materials, 2012. 